\title{
Library Pedagogies: Personal reflections from library practitioners
}

\section{A book review of Aston, S. and Walsh, A. (eds.) (2021) Library Pedagogies: Personal reflections from library practitioners. Huddersfield: Innovative Libraries Press.}

\section{Kimberly Davies Hoffman}

University of Rochester, NY, USA

Keywords: teaching pedagogies; libraries; information literacy; professional development; reflective practice

\section{Overview}

Becoming. This is a book where European and American academic librarians ${ }^{1}$ discuss their journeys of becoming teachers. Many did not pursue librarianship to engage in teaching but found themselves in roles that required instruction, despite a lack of preparation for classroom teaching within their Master of Library and Information Science (MLIS) programs. In a full circle manner, many of the narrative reflections include stories of the librarians' beginnings where, as students, they became scholars, and now consider how their teaching influences the success of current students. They reflect on past influences including personal background, key teachers and other figures that served as models, institutions and ways of learning that made an impact, and scholarship in the field of education and librarianship, all of which have formed deep rooted values which ground the basis of pedagogical pathways.

\footnotetext{
${ }^{1}$ Not all authors identify as a librarian, but they all work within areas of academic success, which includes teaching information literacy and/or research skills.
} 
Each narrative is as unique as the librarians themselves and suggests ways in which they teach as evidenced in the way that they write and present their story. Meaningful moments in their lives and readings by some of the most influential scholars provide insight into what is of most importance to each librarian and how that manifests itself in their current teaching practice.

The reflections are personal and individual. While themes and strategies will begin to connect across the chapters, readers are encouraged to read each of the chapters, in no particular order but to find the titles or author profiles that resonate first and browse the book from there.

\section{Structure and Content}

The anthology of librarian reflections is broken into three main categories:

1. information literacy instruction at the center of one's teaching approach.

2. issues of social justice, power, and authority at the core of one's pedagogical strategies.

3. unique illustrations of other pedagogies and how they are utilised in library settings.

In each section, discussions of one-on-one, small group, lecture hall, embedded, one-shot, full credit course and more informal learning community formats surface, laying the land for all the different ways in which librarians teach and how they are able to apply various pedagogies based on the setting.

It would be difficult to separate out specific chapters per section to discuss their content, as the reader will uncover important but similar themes, values, experiences, and teaching methods across the different chapters. Recurring themes do not detract from the book's appeal; instead, the repetition of ideas leads to a strengthening of understanding in the various pedagogies. Instructional strategies and the why behind them are explained and exemplified in multiple situations, providing a prism-like view of the pedagogies for multidimensional explorations. This is particularly helpful as library professionals at all levels 
and years of experience have much to gain from the personal reflections. There is something within each of the stories for readers to learn from, reflect upon, and consider for their own practice.

Following are key highlights that run through the chapters. For easy identification and access to particular themes and ideas, an index at the back of the book is particularly helpful.

\section{Using metaphors}

Through the authors' stories, readers are taken into the worlds of the Wizard of Oz, Alice in Wonderland, the London Tube, various trailways in nature, and into Hollywood movies like Ferris Bueller's Day Off and Indiana Jones and the Temple of Doom, all with a "suitcase" in hand. The use of metaphor is an effective way to connect the unknown to knowledge that learners already possess. The librarian authors weave in and out of these metaphors to make their points explicit and engage their readers to consider their own frame of reference. Metaphors can create visual and memorable imagery so that the ideas can "stick." For example, in Aston's reference to the Wizard of $\mathrm{Oz}$, she sees her roles as the translator (i.e. mental connections made by the scarecrow), the guide (i.e. the heart and care of the tin man), and the advocate (i.e. the courage to stand up and roar, like the lion). Reference to the Tube in Overn's chapter as her metaphor for feeling lost and/or knowing where she'd like to go and what stops to make will resonate well with readers who have experienced the same emotions as both the developing teacher and the students whom they are guiding. Furthermore, Barker, Walsh, Piper, and Tomlin employ tactile and visual mediums in their teaching where students can represent their ideas in metaphorical ways beyond traditional text.

\section{Feeling a sense of belonging}

This idea surfaces early and often in the chapters, as a nod to bell hooks' notion of "the learning community." Belonging is used and can be read in multiple ways throughout the book. 
The idea first surfaces in terms of a librarian's identity and what skills and duties they expect from the role. Deep dives into teaching responsibilities were not what some librarians bargained for as they entered the field, and perhaps the scholarship of teaching and learning (SoTL) is best left to the university's Learning Developers (or a cross between Instructional Designers and Academic Support in the U.S.). Further, there is internal tension in some of the authors as to whether they are librarians first who happen to teach or teaching librarians as their main focus (chapter by Williams). Such variation in how they see themselves becomes very personal to which group or field they belong or relate to the most.

Second, there are sentiments of belonging to, or playing a key part in, the university system. This is both an issue of loyalty and commitment to an institution that has offered multiple opportunities for professional growth and thus the desire to embody the successes of those efforts (chapter by Aston) and an issue of playing one's part in a university that has made teaching its top priority and mandate (chapter by Newnham).

For students, the feeling that they belong at university or within a learning group is crucial and could ultimately affect their success within the system. Multiple chapters address the notion of power and elitism that exist in higher education. These systems were originally designed for one race, one class, one gender, and with one main approach to learning (i.e., filling the students as empty vessels through professors' knowledge). Librarian accounts from their own backgrounds, but particularly from those of their students, paint an imbalanced view of the "student experience." As a first-generation student, feelings of being lost and alone, of not knowing what to do or where to go to seek help can be paralyzing (chapters by Pajewki, English, and Wolfenden). For BIPOC students (chapter by Kalpin Prescott), the simple visual of predominantly white faces on campus leads them to believe that they don't belong or that they won't be able to succeed. Other factors like personality type (e.g. shy, outgoing), socioeconomic status, abilities and age of the learner, or preferred learning style all present a risk in whether or not a learner feels they belong. 
Teaching strategies that involve feminist learning theory (chapters by Boutin-Cooper, Piepmeier, Pothecary, and Wallis), counter storytelling (chapter by Piper), antiracist pedagogy (chapter by Kalpin Prescott), inquiry-based learning (chapter by McKinney), constructivism, improvisation (chapter by Prior), playful learning approaches (chapter by Walsh), visual learning methods (chapters by Tomlin and Piper), universal design (chapters by Sclafani and Brooks), and e-pedagogies (chapter by Wotherspoon) help to combat students' feelings of isolation or not knowing what they're doing. Within many, if not all, of these methodologies, teacher and student become part of an equalised learning structure where all voices matter, care is taken in the language and actions used, choice is offered to accommodate many individuals' preferences for learning, and content reflects the interests of the class as a whole and provides real-world interactions and inquiries.

Where librarians themselves may struggle (or may have struggled) with feelings of belonging, they are careful to adopt pedagogies that bring everyone to the learning table. By placing the students at the center of learning, they increase those students' chances for academic, social, and digital success through a raised level of confidence and an openness to collaborative scholarly exploration.

\section{Taking risks}

Many chapters begin with a similar story of a newly minted librarian asked to lead their first instructional session. They follow what they have seen in the past - pointing and clicking through a database screen, rushing through PowerPoint slides, and answering their own questions that they have asked of the class. Some authors have benefited from prior coursework or experience in instructional practices, but the majority have not. The power of the pedagogical stories is to see where the authors began and where they are currently. What personal values have they recognised as adding value to their teaching approach? What grounded theories have provided comfort and stability in knowing the "why" behind teaching? What have they learned about their students to make specific decisions in how they will care for and interact with them? 
The stories of trepidation, lack of confidence, and outright "failure" are bolstered by that big leap of faith, that one activity that the authors dared to attempt - close your eyes and hope for the best! The first memorable instance of this is detailed in Barker's chapter where she lugged a heavy suitcase into class and, up until the last moment, deliberated if she would follow the safe, traditional route or take a chance. Exposing the students to an unconventional lesson prompted curiosity, engagement, and of course, a deeper level of learning. Other authors use a strategy of trial and error in their teaching (chapter by Brooks), modeling for students that learning is a process, and "productive failures" indicate that continued, enhanced learning will happen. The development of multimodal projects that leverage non-scholarly formats (e.g. comics, zines) offer students new ways of expressing themselves and the content learned (chapter by Piper), as do regular routines of opening and closing "rounds" where every class participant gets a chance to say what they're thinking (chapter by Pothecary).

The vulnerability of being truly authentic with oneself and particularly with one's students is a risk itself (chapter by Saylor). Hynes focuses his chapter on the value of lecture style, not to buck so many other chapters that highlight the virtues of active learning, constructivism, and other participatory pedagogies but to address a style of teaching that can be equally powerful and that, sometimes, is simply unavoidable. Exposing oneself in the center of a lecture hall can be incredibly intimidating, but Hynes advocates for the art of being true to your personality and opening up conversations regarding the messier side of information - issues that may not have easy answers and for which the "expert" in the room may not possess complete knowledge. The true experts in areas of social media and internet privacy, for example, are likely to be the students.

Finally, the book's authors are to be commended for opening up their hearts and letting their readers into an important, albeit intimate, slice of their world. Transparent and deliberate statements of who they are, where they come from, how they have failed, and what more they have to learn connect readers to the different stories, likely shaking their heads in a sense of familiarity. 


\section{Learning from each other}

With few authors having studied educational theories in their formal MLIS coursework, they detail the numerous ways in which they have grown within their teaching roles. As mentioned above, they turn to their experiences as students thinking of how they learned best. They remember the influential professors, the projects that excited them, the feelings that energised them, and the friends and colleagues who have advised them along the way. Many, particularly in the UK, have pursued post-graduate certificates/diplomas in education. Attendance at institutes, conferences, and countless workshops keep the authors current in new teaching theory and approaches. Researching, reading, trialing, and planning from the literature and frameworks across various disciplines help to identify the most influential studies in teaching and learning (as evidenced by the extensive bibliographies following each chapter). Sharing and brainstorming with colleagues - whether in a library department, a blended office of Learning Development or other campus service points, or with faculty partners - creates a dynamic learning community where the highs, lows, and unknowns of teaching can be discussed. Of course, the act of learning from students may be the most powerful professional development of all. This can certainly happen through assessment measures, but the most enriching comes in the form of getting to know one's students - what they think, what they prioritise, how they're feeling, what interests them most, and what motivates them to learn.

The book concludes with two strategically placed chapters. "Digital literacy in a post-COVID world" was likely included beyond the initial call for participation. It is clear that the different chapters were written before and during the current global pandemic. Some authors address the pivot to online education more than others, but it seems necessary to directly address the future of library pedagogy given the life-changing circumstances of the past year. Wotherspoon argues that online learning is as important in the academic setting as it should be in the working world. While a global lockdown has disrupted typical ways of schooling in higher education, it has also left many unemployed and struggling financially, looking for ways to re-skill and find new jobs that may depend on one's emerging digital capabilities. With a 
different wave of diverse students (e.g. non-traditional, experienced workers, seeking to modernize their skill set), Wotherspoon offers many suggestions for ways to maintain the original values of one's pedagogical approach while adapting from in-person to online, whether synchronous or asynchronous.

Finally, the culminating chapter focuses on "Utlilising coaching to enhance teaching practice." Wolfenden provides the perfect ending to a collection of personal narratives about pedagogical journeys as she encourages readers to now act on what they've read and begin to think through their values and how they might apply to teaching strategies. She offers a number of guided worksheets and questions - perfect for a deeply personal exercise or an investigation into a team's potential direction for future shared pedagogical philosophies. Questions are open-ended for ourselves or for colleagues we may be coaching. Wolfenden further applies the coaching approach to students so that they, too, can realise their potential.

\section{Summary}

Within the introduction of Library pedagogies: Personal reflections from library practitioners, editors Sam Aston and Andrew Walsh state their aim of "inspiring the reader to reflect upon their own beliefs, values, experiences, and wider pedagogical approaches, in order to write their own personal pedagogies." The diversity in stories and author experiences are sure to speak to readers where they can't help but begin to reflect on their current practices. Familiar tales, recognisable frameworks, theories, and scholars, and the inspiring success when teachers and students connect as mutually trusted learners will ring true for readers, no matter at what stage they are in their career. For those readers who have thought carefully about their pedagogical approach, there is more to learn from this book. For new librarians who may stand at the center of the lecture hall ready to run the "typical" lesson based on what they have observed for most of their years as a learner, this book may jump-start their learning process so they don't have to struggle through years of uncertainty and uninspired results. This book adds to the growing literature calling on MLIS programs to prioritise formal teacher training, since the majority of library jobs entail teaching and learning, if even on an 
indirect or one-to-one scale. Until then, the personal narratives of library pedagogies contribute another important piece to the scholarly conversation and prompt librarians to reflect and act upon what they've read and what they do.

\section{Author details}

Kimberly Davies Hoffman is the Director of Learning Initiatives for the River Campus Libraries at the University of Rochester. She has been teaching in a library role since 1997 with the heaviest classroom responsibility happening between 2000-2014 at SUNY Geneseo. Her publications and conference presentations focus on issues of librarian professional development, collaborative relationships between faculty and librarians, instructional design in libraries, and most recently, open pedagogical practices. 